\title{
DIAGNÓSTICO DE BEM-ESTAR EM CAMUNDONGOS E RATOS DE BIOTÉRIOS NO ESTADO DO PARANÁ
}

\author{
(Animal welfare diagnosis in mice and rats from animal facilities in the state of Paraná) \\ Bernardo Graça Fatori Deguchi ${ }^{1}$, Vanessa Carli Bones², Carla Forte Maiolino Molento ${ }^{1}$ \\ Universidade Federal do Paraná ${ }^{\text {, }}$ Conselho Regional de Medicina Veterinária do Paraná (CRMV-PR) ${ }^{2}$ \\ ${ }^{1}$ Corresponding author: vcb.vete@gmail.com
}

RESUMO: Os animais de laboratório são amplamente utilizados para contribuir com o desenvolvimento da ciência. Ratos e camundongos estão entre os principais grupos taxonômicos utilizados para tal fim, sendo os animais principalmente provenientes de biotérios de criação. Nestes locais eles são mantidos sob estrito controle ambiental, visando diminuir a variabilidade dos resultados das pesquisas. É importante conhecer o grau de bem-estar desses animais, pois tal fator tem implicações diretas no comportamento ético em relação aos outros seres vivos e também quanto à qualidade dos resultados obtidos. $O$ objetivo deste trabalho foi verificar o grau de bem-estar animal (BEA) dos ratos e camundongos em quatro biotérios ( $A, B, C$ e $D)$ de instituições de ensino do Estado do Paraná. Para todos os biotérios visitados os grupos de indicadores sanitários e psicológicos foram considerados severamente comprometidos e 0 grupo de indicadores comportamentais moderadamente comprometido. O grupo de indicadores nutricionais foi moderadamente satisfatório nos biotérios $A, B$ e $D$ e completamente satisfatório no biotério C. O grupo de indicadores ambientais foi severamente comprometido nos biotérios $A$ e $B$ e moderadamente comprometido nos biotérios $\mathrm{C}$ e $\mathrm{D}$. Itens de enriquecimento ambiental não são utilizados e medidas de redução da dor durante a eutanásia não são tomadas em nenhum dos biotérios visitados, sugerindo que a atuação nestes dois pontos deve ser prioritária. Em geral, medidas para a melhoria de BEA nos biotérios do Estado do Paraná são urgentes.

Palavras-chave: animais de laboratório, biotério, enriquecimento ambiental, eutanásia.

\begin{abstract}
Laboratory animals are widely used to contribute to the development of knowledge. Rats and mice are among the main taxonomic groups for such purposes and these animals are bred mostly in animal breeding facilities. In these facilities they are kept under strict environmental control in order to decrease variability of the research's results. It is imperative to recognize the welfare of these animals, due its implications on ethical behavior towards other living beings as well as the quality of results. The objective of the present work was to perform a welfare assessment in rats and mice in four animal breeding facilities (A, B, C and D) of educational institutions in the State of Paraná. For all facilities visited the health and psychological groups of indicators were considered severely compromised and the behavior group of indicators was moderately compromised. The nutritional group of indicators was moderately satisfactory in locations A, B and D and fully satisfactory in $C$. The environmental group of indicators was severely compromised in locations $A$ and $B$ and moderately compromised in $C$ and $D$. Environmental enrichment items are not used and measures to reduce pain during euthanasia are not performed in any of the visited locations, suggesting that the actuation in these two areas should be a priority. In general, measures to improve animal welfare in animal facilities in the State of Paraná are urgent.
\end{abstract}

Keywords: laboratory animals, animal breeding facilities, environmental enrichment, euthanasia. 


\section{INTRODUÇÃO}

A utilização de animais em laboratórios pode contribuir para 0 conhecimento e a melhoria do bemestar animal (BEA) e humano. Cada espécie e cada linhagem de animais apresenta características e necessidades específicas. Quando o grau de BEA é baixo há aumento na variabilidade dos dados, provocando uma difícil reprodução do estudo e diminuição da sua credibilidade; assim, pode ser necessário aumentar o número de animais utilizados (Austrália, 2008), o que contradiz 0 mundialmente conhecido Princípio dos Três Rs, do inglês Substituição e Redução de Animais e Refinamento de procedimentos utilizando animais (Russell \& Burch, 1992).

Os vertebrados são seres capazes de vivenciar sentimentos como dor, prazer e sofrimento (Broom, 2014). Estima-se que sejam utilizados 115,3 milhões de animais vertebrados anualmente para experimentação no mundo, sendo o uso no Brasil estimado em 1.16 milhões de animais (Taylor, 2008). Bones e colaboradores (2010) avaliaram artigos científicos de revistas publicadas no Estado do Paraná em 2006 por meio do método da amostragem bibliográfica e obtiveram o total subestimado de 216.223 animais vertebrados utilizados em pesquisas naquele ano. O Brasil está progredindo na área da regulamentação do uso de animais usados em laboratório; um marco importante foi a criação do Conselho Nacional de Controle de Experimentação Animal (CONCEA; Brasil, 2008). Neste sentido é importante ressaltar a necessidade de manter registros relativos aos animais usados; tal ação é fundamental para que um país possa implementar políticas para a aplicação do Princípio dos Três Rs (Russell \& Burch, 1992).

Os animais utilizados podem passar por alterações genéticas e ser submetidos a procedimentos experimentais, os quais por sua vez podem gerar alto grau de dor e sofrimento. De forma crescente a sociedade tem apresentado demanda por melhores condições no tratamento dos animais, e portanto, o conhecimento do grau de bem-estar dos animais em biotérios parece relevante. Pouco se conhece sobre o grau de BEA dos animais de biotérios devido ao fluxo de pessoas restrito a funcionários e ao caráter geral das regras às quais os biotérios estão sujeitos. Este trabalho teve o objetivo de verificar o grau de BEA de camundongos e ratos em biotérios de cinco instituições de ensino do Estado do Paraná.

\section{MATERIAL E MÉTODOS}

O projeto foi aprovado pela CEUA do Setor de Ciências Agrárias da Universidade Federal do Paraná sob o protocolo no. 019/2011 em 2011. Foram realizadas visitas programadas em quatro biotérios de instituições de ensino do Paraná, em 2012, identificados como A, B, C e D. As visitas foram realizadas às segundasfeiras, com o objetivo de encontrar os biotérios em condições semelhantes de limpeza e conservação.

O diagnóstico foi realizado seguindo os itens de uma ficha de avaliação criada especificamente para ratos e camundongos, baseados nas Cinco Liberdades do BEA (FAWC, 1993), em guias internacionais para cuidados de animais de laboratório (NAS, 2010) e na ficha de perícia de BEA criada para outras espécies (Hammerschmidt, 2012). Assim, foi estabelecida uma ficha de diagnóstico de bem-estar de ratos e camundongos de laboratório. $\mathrm{O}$ documento foi separado em seis seções: características gerais e grupos de indicadores nutricionais, ambientais, sanitários, comportamentais e psicológicos (Tabela 1). 


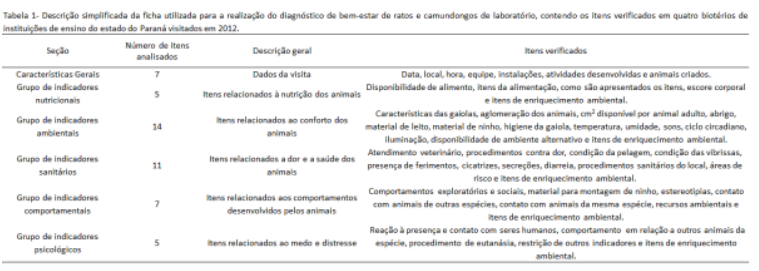

Os resultados de cada grupo de indicadores foram classificados em uma das cinco categorias a seguir: (1) severamente comprometido; moderadamente comprometido; intermediário; (4) moderadamente satisfatório; e (5) completamente satisfatório. Na ocorrência de resultados severamente comprometidos para qualquer grupo de indicadores, automaticamente os resultados foram considerados severamente comprometidos também para o grupo de indicadores psicológicos. Em todos os biotérios, foi considerado o relato dos funcionários e também escolhida aleatoriamente uma sala contendo animais para a realização do diagnóstico completo e visualização de todos os indivíduos.

\section{RESULTADOS E DISCUSSÃO}

Todos os biotérios estão localizados em áreas individuais com entrada restrita aos funcionários e pessoas autorizadas. Em 2012, no biotério $\mathrm{A}$ foram criados e mantidos 630 ratos e 170 camundongos para a experimentação; no biotério $\mathrm{B}$, foram criados 4000 ratos e 900 camundongos que foram utilizados por sete instituições de pesquisa; no biotério $C$, foram criados e mantidos 565 ratos para a experimentação; no biotério $D$ foram produzidos 350 ratos para experimentação. Quanto às salas sorteadas para o diagnóstico completo, no biotério $A$ a sala continha 73 camundongos, no biotério B 668 camundongos, no biotério $C 120$ ratos e no biotério $D 87$ ratos.

Nos biotérios $A$ e $B$, técnicos com formação no Ensino Médio eram responsáveis pela troca e realocação dos animais nas gaiolas; no biotério $\mathrm{C}$, um estudante de graduação em Ciências Biológicas e outro estudante de mestrado em Ciências Biológicas, e no biotério $D$ estagiários estudantes de graduação em Ciências Biológicas. O treinamento dos cuidadores foi realizado principalmente nos locais de trabalho, o que pode constituir uma fragilidade, parecendo haver possibilidade de benefícios ao se promover um treinamento mais formal e monitorado por organismos federais.

Em relação à avaliação do grupo de indicadores nutricionais, a forma padrão de alimentação em biotérios é ad libitum. Os camundongos e ratos avaliados recebiam água em garrafas que ficavam sobre a grade de retenção e ração peletizada à vontade, exceto no biotério $\mathrm{C}$ em que eram disponibilizados $50 \mathrm{~g}$ de ração/rato/dia. Apesar de haver intervalos entre as reposições dos itens nutricionais, os animais não sofriam restrição alimentar. Apesar da oferta contínua de alimentos ser relevante para o BEA imediato, estudos indicam que a disponibilidade restrita de comida e calorias melhora diversos parâmetros biológicos (Goto et al., 2007). A restrição alimentar também diminui a incidência e severidade de doenças não-neoplásicas e neoplásicas, aumentando a longevidade dos animais (Roe et al, 1995). Portanto, a dieta balanceada além de proporcionar controle nutricional pode vir a prevenir a eutanásia antecipada, uma vez que os animais apresentam redução de doenças.

Quanto ao grupo de indicadores sanitários, no biotério $\mathrm{A}$, a limpeza e a troca dos materiais eram realizadas na segunda e quinta-feira. No biotério $B$ a troca dos materiais era realizada na segunda e quinta-feira e a limpeza dos equipamentos na segunda, terça e quarta-feira. No biotério $C$ as trocas das 
gaiolas eram feitas durante dois dias consecutivos, na quarta e quinta-feira com a retirada do material de descarte e as garrafas de água trocadas na sextafeira. No biotério D a limpeza e troca por gaiolas limpas eram realizadas na segunda e quinta-feira nos animais de estoque e na segunda, quarta e sextafeira nas matrizes. $O$ biotério $C$ foi $O$ único a realizar a limpeza uma única vez por semana e somente neste local nenhum animal apresentou ferimentos. Tal informação difere de Burn et al., 2006, que indica que a frequência de limpeza tem pouca influência na ocorrência de agressões. É possível que - número reduzido de animais analisados e a diferença nas características gerais dos locais tenham tido influência adicional na ocorrência das agressões. Entretanto, os resultados são coerentes com o fato de que as marcas olfatórias deixadas no substrato permitem a manutenção da estabilidade social e quando estas são interrompidas há menor tolerância para com os animais que não são reconhecidos como parte do grupo, aumentando as agressões (Hurst et al., 1993). As gaiolas apresentaram bom estado de limpeza com poucas regiões úmidas, exceto no biotério $A$, que apresentou grande formação de placas compactas de sujeira, umidade excessiva no substrato e odor intenso de amônia.

Os processos sanitários utilizados pelos biotérios analisados estão em concordância com a legislação (CTNBio, 2006). Devido às atividades com risco biológico, os biotérios podem receber a visita de órgãos de fiscalização sanitária. $O$ biotério $A, B$ e $D$ recebiam anualmente a visita da Vigilância Sanitária, o biotério $\mathrm{C}$ não relatou a visita de órgãos fiscalizadores. Em todos os locais 0 atendimento veterinário é realizado sem frequência determinada, ocorrendo quando há suspeita de doenças exceto complicações inerentes ao envelhecimento do animal. A eutanásia é o procedimento padrão quando há indícios de problemas com a saúde do animal, como a queda de pelos, pelos excessivamente eriçados ou quando detectados ferimentos muito graves, tumores e envelhecimento. $\mathrm{O}$ controle e a prevenção da dor por fármacos não é realizado, nem nos procedimentos de eutanásia.

No biotério $A$, um animal macho mantinha um dos olhos completamente fechado e três fêmeas apresentavam ferimentos na vagina (Tabela 2). No biotério $B$ um animal estava com leves ferimentos no focinho, um estava com múltiplos ferimentos nas orelhas, focinho e ausência de vibrissas e três estavam com os pelos eriçados (Tabela 2). No biotério $C$ não foram encontrados animais com ferimentos e no biotério $D$ um animal apresentava ferimentos nas orelhas. Apenas no biotério D o animal ferido estava em isolamento. Em todos os biotérios são realizadas amostragens de fezes para o monitoramento da existência de parasitos internos. A inexistência de animais com problemas sanitários no biotério $\mathrm{C}$ pode ser consequência da maior disponibilidade de espaço por animal (Tabela 2). Os menores espaços por animal (Tabela 2) nos biotérios $A$ e $B$ podem levar $a$ condições de aumento de doenças e morte. O efeito do espaço disponível por animal na ocorrência de problemas sanitários merece um estudo detalhado de correlação. 
No que se refere ao grupo de indicadores ambientais, as gaiolas de manutenção são brancas e translúcidas, com dois tamanhos: de $18 \mathrm{~cm}$ de largura, $28 \mathrm{~cm}$ de comprimento e 12,5 $\mathrm{cm}$ altura com $504 \mathrm{~cm}^{2}$ e com $33 \mathrm{~cm}$ de largura, $40 \mathrm{~cm}$ de comprimento, $16,5 \mathrm{~cm}$ altura e $1320 \mathrm{~cm}^{2}$. Estas gaiolas podem prover aos animais o tamanho mínimo necessário para o conforto (NSW, 2004; NAS, 2010) desde que a quantidade de

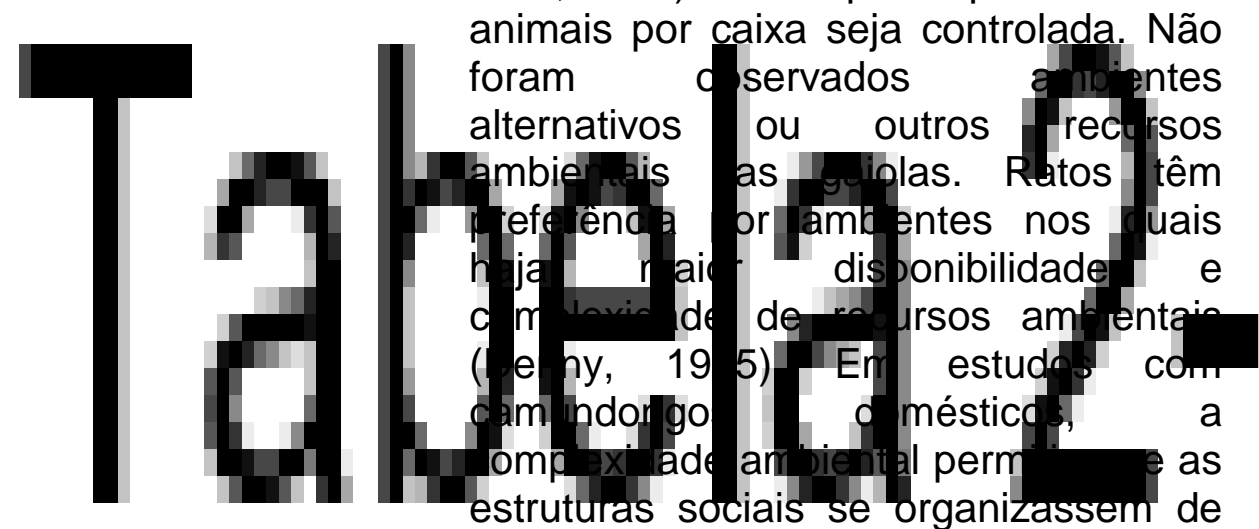
forma mais adequada (Gray et al., 2000). Ainda, nos biotérios estudados não havia abrigo para a proteção contra a luz ou outros animais. Camundongos tem alta motivação por abrigo (Sherwin, 1996). A ausência de enriquecimento ambiental (EA) representa importante limitação para o bem-estar dos animais.

O substrato utilizado para forrar o chão da caixa nos locais analisados era a maravalha de pinus, com objetivo de facilitar a absorção da umidade de urina e fezes e servir como leito para os animais. O material utilizado como cama pode variar bastante nos roedores (Burn et al., 2006; CCAC, 2003; NAS, 2010), entretanto, a grande disponibilidade de maravalha de pinus no Brasil favorece a sura urnzaçau. ivau cram disponibilizados outros materiais para ninho exceto a maravalha, apresentando grande variação de tamanho de partícula em todos os biotérios analisados.

Em todos os locais era realizado o monitoramento da umidade relativa do ar e da temperatura, com o controle da temperatura por aparelhos de ar 
condicionado. As temperaturas variaram de $21,2^{\circ} \mathrm{C}$ a $24,0^{\circ} \mathrm{C}$ e a umidade relativa do ar de $50,0 \%$ a $80,0 \%$. A temperatura e a umidade ideais para ratos são de $20-25^{\circ} \mathrm{C}$ e $45-65 \%$ e para camundongos 22-25C e 50-70\% (CCAC, 2003). A temperatura do microambiente é em parte controlada pelos animais; em especial quando dispõem de material para ninho eles tem a possibilidade de organizar o ambiente de maneira que a temperatura esteja mais adequada para o seu conforto (Gaskill, 2013).

Não havia monitoramento sonoro constante, tanto para sons audíveis ao ser humano $(0,02 \mathrm{kHz}-20 \mathrm{kHz})$ quanto para ultrassons (acima de $20 \mathrm{kHz}$ ). No biotério $B$ ocasionalmente eram realizadas medições de decibéis quando algum fator externo ao biotério estiver interferindo, com subsequente acompanhamento do comportamento, taxa de sobrevivência e tamanho da prole. Roedores podem perceber frequências sonoras de $0,25 \mathrm{~Hz}$ a 80 $\mathrm{kHz}$ (Kelly e Masterton, 1977). O ambiente acústico nos laboratórios está associado às atividades de manutenção e 0 estresse potencial que podem causar são agravados pela predominância do silêncio na maior parte do tempo (Milligan et al., 1993). A movimentação de portas, cadeiras e gaiolas, a utilização de torneiras e aparelhos eletrônicos, além dos sons que podem ser percebidos pelos seres humanos, são também fontes de sons ultrassônicos (Sales et al., 1988). Sons disruptivos causam maior perturbação que sons contínuos (Inglis et al, 2010). Os sons do ambiente podem alterar parâmetros fisiológicos, comportamentos e ciclo circadiano dos animais (Milligan et al., 1993); tais alterações por sua vez podem levar à diminuição do grau de BEA. Na impossibilidade de medição do referido parâmetro, a estratégia pode ser reduzir as possíveis fontes sonoras.
Em todos os locais visitados, os filhotes eram mantidos com as mães até o desmame, independentemente da quantidade de animais por gaiola. Desta forma, devido ao tamanho variável da ninhada, pode ocorrer aglomeração excessiva. As recomendações para camundongos variam de $180 \mathrm{~cm}^{2} /$ filhote mais $300 \mathrm{~cm}^{2}$ para a mãe e 160-330 $\mathrm{cm}^{2}$ para filhotes e mãe (CCAC, 2003; Baumans, 2010; NAS, 2010). Nos biotérios $A$ e $B$, a sala sorteada para diagnóstico completo possuía pelo menos uma caixa com disponibilidade de espaço por camundongo em condições abaixo do recomendado (CCAC, 2003; NSW, 2004; Baumans, 2010; NAS, 2010), caracterizando um ponto crítico de BEA. Nas outras lotações não foram notados espaços inadequados. Os camundongos são proporcionalmente os animais com menor espaço recomendado por guias de manutenção de animais (Hackbarth, 2012). Os casos encontrados em que os animais eram mantidos em espaço menor que o recomendado merecem atenção e resolução.

Com relação ao grupo de indicadores comportamentais, os camundongos

principalmente realizavam exploratórios de se direcionar para fora da caixa e farejar o substrato; os ratos agiam com menor agitação. Em cada sala eram mantidos apenas animais da mesma espécie, havendo contato físico, visual e olfativo intraespecíficos. Os animais de sexos opostos estavam em contato apenas quando jovens ou quando mantidos para formação de casais. Animais eram mantidos isolados nos biotérios $B$ e $D$. Em isolamento social roedores podem desenvolver distúrbios comportamentais (Arakawa, 2005). Quando por algum motivo há necessidade de manter um animal em isolamento social, pode-se utilizar material de ninho para desencadear os comportamentos relacionados ao 
descanso aumentando a sensação de segurança (Van Loo et al., 2004) e promover o controle térmico adequado (Gaskill, 2013). Tais medidas podem mitigar os efeitos negativos do isolamento para o BEA.

Durante as visitas foram presenciados alguns comportamentos agonísticos entre os camundongos nos biotérios $A$ e $B$. Houve intensa movimentação no substrato e na grade de contenção com vocalizações de características agonísticas e movimentação agressiva. $O$ ideal de agrupamento para camundongos é de três indivíduos por caixa devido à diminuição nos comportamentos agressivos e melhor estabilidade social (Van Loo et al., 2003). É importante que a formação dos grupos seja monitorada para que sejam mantidos grupos estáveis. Grupos de animais com estruturas sociais instáveis ou inapropriadas podem afetar negativamente $o$ comportamento, os sistemas endócrino e imune dos animais (Olsson e Westlund, 2007) e aumentar a ocorrência de agressões (Hurst et al., 1993).

De forma geral, o ambiente de manutenção dos animais foi considerado pobre, pois não havia estrutura além da básica. O EA visa melhorar a qualidade de vida de animais cativos, aumentando a amplitude e diversidade de oportunidades comportamentais provendo ambientes estimulantes e complexos (Shepherdson, 1998). Quando o EA é utilizado, os estudos apresentam menor variância em testes comportamentais (Baumans, 2010). No presente estudo, não foi presenciado comportamento estritamente estereotípico; entretanto, as fêmeas de camundongos do biotério A se movimentaram com alta frequência penduradas à grade das gaiolas. Nos casos em que há comportamentos estereotípicos, o EA pode reduzir sua ocorrência (Gross et al., 2012). A utilização de EA logo após o desmame reduz a ocorrência de estereotipias e os efeitos são mantidos mesmo quando os animais foram mantidos sem enriquecimento (Jones et al., 2011).

Os indicadores do grupo psicológico são influenciados pelos outros indicadores. Os animais não demonstraram comportamentos de esquiva ou agressividade anormais durante a manipulação pelos funcionários e se mostraram alertas com a proximidade dos seres humanos, realizando comportamento exploratório. Entretanto, nos biotérios A e B foram encontradas gaiolas com quantidade de animais por gaiola acima do recomendado, e nos biotérios $B$ e $D$ animais foram mantidos isolados. Tais resultados sugerem a ocorrência de sofrimento psicológico nos animais.

No biotério $A, B$ e $C$ a eutanásia é realizada em câmara de $\mathrm{CO}^{2}$ e no biotério $D$ é realizada por decapitação com guilhotina. Em nenhum caso são administradas medicações para a prevenção da dor durante a eutanásia. Segundo o Conselho Federal de Medicina Veterinária (CFMV, 2012), a forma recomendada para ratos e camundongos é a utilização de anestesia geral prévia com barbitúricos ou outros anestésicos injetáveis ou inalatórios seguidos de procedimento para assegurar a morte. A utilização de nitrogênio, argônio, dióxido de carbono, T61 (anestésico, paralisante muscular e inibidor da respiração), deslocamento cervical e decapitação por guilhotina são aceitos sob restrição. Segundo 0 CONCEA (2018), são recomendáveis ${ }^{1}$ barbitúricos por via intravenosa ou intraperitoneal $^{2}$, anestésicos gerais

\footnotetext{
$1 \quad$ Após a perda do reflexo corneal, os métodos podem ser complementados por cloreto de potássio associado ou não a bloqueador neuromuscular, ambos por via intravenosa.

$2 \quad$ Em casos excepcionais quando da impossibilidade de administração intravenosa.
} 
intravenosos, anestésicos inalatórios, sobredosagem da associação de anestésicos dissociativos e agonistas de adrenorreceptores alfa-2 administrada pelas vias intravenosa, intramuscular, ou intraperitoneal ${ }^{2}$; são aceitos com restrição dióxido de carbono ${ }^{3}$, deslocamento cervical, decapitação com equipamentos comerciais de uso específico tipo guilhotina, micro-ondas específicos para esta finalidade, congelamento rápido ou nitrogênio líquido para fetos e neonatos de ratos e camundongos, atordoamento seguido de exsanguinação 4 .

Embora sejam procedimentos aceitos, ratos agem aversivamente na presença argônio, monóxido de carbono e dióxido de carbono (Makowska et al., 2009), sendo necessário buscar outras formas de eutanásia. $\mathrm{O}$ procedimento de eutanásia é um dos principais momentos em que os animais podem vir a vivenciar dor e sofrimento e, portanto, sua adequação é prioritária do ponto de vista de BEA.

A partir da avaliação dos biotérios com base nos grupos de indicadores, foi possível realizar o diagnóstico de BEA final (Figura 1). As principais questões relacionadas à diminuição do BEA nos biotérios analisados foram a falta de tratamento médico, os procedimentos de eutanásia sem anestesia prévia e a falta de EA. Os ambientes pouco complexos, ainda, não permitem vasto repertório comportamental. Todos são pontos críticos passíveis de atuação para melhoria de BEA.

3 Desde que seguidas as recomendações das diretrizes da prática de eutanásia (referência citada) referentes ao item 8.1.1.2.

$4 \quad$ Apenas em animais silvestres em situações de campo. 


\section{CONCLUSÕES}

Os resultados de quatro biotérios paranaenses indicam que parâmetros ambientais importantes para o BEA não são monitorados. Ainda, o grupo de indicadores sanitários mostrou-se severamente comprometido devido à inexistência de tratamento da dor ou sua prevenção no caso da eutanásia. Itens de EA não são utilizados nos locais visitados e há ocorrências de espaço por animal abaixo do recomendado. A atuação direta nos pontos críticos verificados é urgente para induzir melhorias significativas no BEA de animais de laboratório no Brasil.

\section{AGRADECIMENTOS}

Os autores agradecem à CAPES - Coordenação de Aperfeiçoamento de Pessoal de Nível Superior pela concessão de bolsa de estudos, às equipes dos biotérios visitados, à equipe do LABEA - Laboratório de Bem-estar Animal/UFPR e a todos os respondentes.

\section{REFERÊNCIAS}

ARAKAWA, H. Interaction between isolation rearing and social development on exploratory behavior in male rats. Behavioural Processes, v.70, n.3, p.223-234, 2005.

AUSTRÁLIA. Guidelines to promote the wellbeing of animals used for scientific purposes: The assessment and alleviation of pain and distress in research animals. Camberra: National Health and Medical Research Council, 2008. 189p.

BAUMANS, V. The laboratory mouse. In: HUBRECHT R.; KIRKWOOD J. The UFAW Handbook on the Care and Management of Laboratory and Other Research Animals. 8 ed. Oxford: 
Blackwell Publishing, 2010, Cap. 21, p.276-310.

BONES, SANS \& MOLENTO. An Estimation of the Extent of Animal Use in Research in Brazil, as Determined by Bibliographic Sampling from Journals Published in the State of Paraná. Alternatives to Laboratory Animals, v.38, p.29-37, 2010.

BURN, C.C.; PETERS, A.; DAY, M.J. et al. Long-term effects of cage-cleaning frequency and bedding type on laboratory rat health, welfare, and handleability: a cross-laboratory study. Laboratory Animals, v.40, n.4, p.353370, 2006.

BRASIL. Lei $\mathrm{n}$ - 11.794, de 8 de outubro de 2008. Disponível em: https://www.in.gov.br/imprensa/visualiza/ index.jsp?jornal $=1$ \&pagina $=1$ \&data $=09 / 1$ 0/2008. Acesso em: 10/10/2008.

BROOM, D. Sentience and animal welfare. Wallingford: CABI, 2014. 185p.

CANADIAN COUNCIL ON ANIMAL CARE- CCAC. Guidelines on: laboratory animal facilitiescharacteristics, design and development. Ottawa, ON, 2003. 108p. Disponível em: http://www.ccac.ca/Documents/Standard s/Guidelines/Facilities.pdf Acesso em: 16/11/2013.

COMISSÃO TÉCNICA NACIONAL DE BIOSSEGURANÇA- CTNBio. Resolução Normativa $n^{\circ} 2,27$ de novembro de 2006. Diário oficial da União. Brasília, DF, 2006. 16p.

CONSELHO

NACIONAL DE CONTROLE DE EXPERIMENTAÇÃO ANIMAL- CONCEA. Diretriz da prática de eutanásia do CONCEA. 2018. 49p.

CONSELHO FEDERAL MEDICINA VETERINÁRIA- CFMV. Resolução $\mathbf{n}^{\circ}$
1000 de 11 de maio de 2012. Diário Oficial da União. Brasília, DF, 2012. 9p.

DENNY, M.S. The rat's long-term preference for complexity in its environment. Animal Learning and Behavior, v.3, n.3, p.245-249, 1975.

FARM ANIMAL WELFARE COUNCILFAWC. Report on priorities for animal welfare research and development. London, UK, 1993. 30p.

GASKILL, B.N. The naked truth: breeding performance in nude mice with and without nesting material. Applied Animal Behaviour Science, v.143, n.24, p.110-116, 2013.

GOTO, S.; TAKAHASHI, R.; RADAK, Z. et al. Beneficial biochemical outcomes of late-onset dietary restriction in rodents. Annals of the New York Academy of Sciences, v.1100, p.431-441, 2007.

GRAY, S.; JENSEN, S.P.; HURST, J.L. Structural complexity of territories: preference, use of space and defence in commensal house mice, Mus domesticus. Animal Behaviour, v.60, n. 6, p.765-772, 2000.

GROSS, A.N.; RICHTER, S.H.; ENGEL, A.K.J. et al. Cage induced stereotypies, perseveration and the effects of environmental enrichment in laboratory mice. Behavioural Brain Research, v.234, n.1, p.61-68, 2012.

HACKBARTH, H. Environmental improvement because not every enrichment makes sense. In: LABORATORY ANIMAL SCIENCE BIOCONFERENCE LIVE, conferência online, 2012.

HAMMERSCHMIDT, J. Desenvolvimento e aplicação de perícia de bem-estar animal. 2012. Curitiba, 145f. Dissertação (Mestrado em Ciências Veterinárias) - Curso de 
Pós-Graduação em Ciências Veterinárias, Universidade Federal do Paraná.

HURST, J.L.; FANG, J.; BARNARD, C.J. The role of substrate odours in maintaining social tolerance between male house mice, Mus musculus domesticus. Animal Behaviour, v.45, n.5, p.997-1006, 1993.

INGLIS, I.R.; MATHEWS, F.; HUDSON, A. Wild mammals. In: R. HUBRECHT; J. KIRKWOOD (ed) The UFAW Handbook on The Care and Management of Laboratory and Other Research Animals. Oxford, UK: Blackwell Publishing Ltd. p. 246-262, 2010.

JONES, M.A.; MASON, G.; PILLAY, N. Early environmental enrichment protects captive-born striped mice against the later development of stereotypic behaviour. Applied Animal Behaviour Science, v.135, n.1-2, p.138-145, 2011.

KELLY, J.B., MASTERTON, B. Auditory sensitivity of the albino rat. Journal of Comparative Psychology, v.91, n.4, p.930-936, 1977.

MAKOWSKA, I.J.; VICKERS, L.; MANCELL, J. et al. Evaluating methods of gas euthanasia for laboratory mice. Applied Animal Behaviour Science, v.121, n.3-4, p.230-235, 2009.

MILLIGAN, S.R.; SALES, G.D.; KHIRNYKH, K. Sound levels in rooms housing laboratory animals: an uncontrolled daily variable. Physiology \& Behavior, v.53, n.6 p.1067-1076, 1993.

NATIONAL ACADEMY OF SCIENCESNAS. Guide for the care and use of laboratory animals. 8.ed. Washington: National Academies Press, 2010. 220p.
NEW SOUTH WALES AGRICULTURE ANIMAL RESEARCH REVIEW PANELNSW. Guidelines for the housing of rats in scientific institutions. Guideline 20. Orange: NSW Department of Primary Industries, 2004.

OLSSON, I.A.S.; WESTLUND, K. More than numbers matter: the effect of social factors on behavior and welfare of laboratory rodents and non-human primates. Applied Animal Behaviour Science, v.103, n.3-4, p.229-254, 2007.

ROE, F.J.C. , LEE , P.N. , CONYBEARE G.; KELLY, D.; MATTER, B.; PRENTICE, D.; TOBIN, G. The Biosure Study: Influence of composition of diet and food consumption on longevity, degenerative diseases and neoplasia in wistar rats studied for up to 30 months post weaning. Food and Chemical Toxicology, 33, 1S - 100S, 1995

RUSSELL, W.M.S.; BURCH, R.L. The principles of humane experimental technique. London: Hiperion Books, $1992 . \quad$ Disponível em: http://altweb.jhsph.edu/pubs/books/hum ane_exp/het-toc. Acesso em: 20/04/2017.

SALES, G.D.; WILSON, K.L.; SPENCER, K.E.V. et al. Environmental ultrasound in laboratories and animal houses: a possible cause for concern in the welfare and use of laboratory animals. Laboratory Animals, 22, 369375, 1988.

SHEPHERDSON, D.J. Introduction: Tracing the path of environmental enrichment in zoos. In: SHEPHERDSON, D.J.; MELLEN, J.D.; HUTCHINS, M. (Ed). Second Nature: Environmental enrichment for captive animals. California: Smithsonain Books, 1998. Cap. 1, p.1-12.

SHERWIN, C.M. Laboratory mice persist in gaining access to resources: a 
method of assessing the importance of environmental features. Applied Animal Behaviour Science, v.48, n.3-4, p.203214, 1996.

TAYLOR, K.; GORDON, N.; LANGLEY, $G$. et al. Estimates for worldwide laboratory animal use in 2005. Alternatives to Laboratory Animals, v.36, p.327-342, 2008.

VAN LOO, P.L.P.; VAN ZUTPHEN, L.F.M.; BAUMANS, $V$. Male management: coping with aggression problems in male laboratory mice. Laboratory Animals, v.37, n4, p.300313, 2003.

VAN LOO, P.L.P.; BLOM, H.J.M.; MEIJER, M.K. et al. Assessment of the use of two commercially available environmental enrichments by laboratory mice by preference testing. Laboratory Animals, v.39, n.1, p.58-67. 2004.nimals, v.39, n.1, p.58-67, 2004. 